Eur. J. Clin. Chem. Clin. Biochem.

Vol. 32, 1994, pp. 441-447

(c) 1994 Walter de Gruyter \& Co.

Berlin - New York

\title{
Leukocyte Proteinase Release During Storage of Red Cell Concentrates ${ }^{1}$ )
}

\author{
By H.-J. Hertfelder ${ }^{1}$, Vera Süwer ${ }^{2}$, Smilja Popov-Cenic ${ }^{1}, H$. Tschesche ${ }^{2}$ and P. Hanfland ${ }^{1}$ \\ 1 Institut für Experimentelle Hämatologie und Transfusionsmedizin, Universität Bonn, Germany \\ 2 Fakultät für Chemie, Lehrstuhl Biochemie, Universität Bielefeld, Germany
}

(Received June 25, 1993/March 7, 1994)

Summary: The release of polymorphonuclear leukocyte proteinases in buffy-coat-depleted red cell concentrates was examined during a storage period of 35 days. Collagenase, gelatinase and elastase predominantly induce breakdown of connective tissue. However, when released by cell disintegration during red cell concentrate storage, the considerable proteolytic activities of these enzymes might influence the quality of the stored blood. During the observation period a considerable decrease in the polymorphonuclear leukocyte count was observed, accompanied by increases in the levels of collagenase, gelatinase and elastase. Compared with the enzyme levels on the day of red cell concentrate preparation, collagenase increased 20-fold, gelatinase 6-fold and elastase 100-fold during the storage period. When cells were treated with the chemoattractant hexapeptide, $\mathrm{N}$-formyl-nle-leu-phe-nle-tyr-leu, and the degranulation promoting cytochalasin $\mathrm{B}$, gelatinase exhibited the highest secreted concentration in the freshly prepared red cell concentrate, exceeding the maximum of spontaneously released elastase by 4- to 6-fold. However, these compounds stimulated enzyme release only during the first day after red cell concentrate preparation. Thereafter, no differences between stimulated and non-stimulated samples were observed. The data indicate that polymorphonuclear leukocytes contain a large storage pool of proteolytic enzymes. These enzymes together with other polymorphonuclear leukocyte enzymes, e.g. hydrolases and oxidoreductases, might alter the erythrocyte membrane surface and thus influence the storage quality of the prepared red cell concentrate.

\section{Introduction}

The removal of the buffy-coat is an important step in the preparation procedure of rèd cell concentrates from freshly donated whole blood (fresh whole blood). During this step the total leukocyte and platelet content of the donated blood unit is considerably depleted, but appreciable numbers of leukocytes still remain in the red cell concentrate.

The intracellular lysosomes of polymorphonuclear leukocyte contain a variety of proteolytic enzymes ${ }^{2}$ ), which are necessary for intracellular catabolism, degradation of

\footnotetext{
') This work was supported by the special research programme SFB 223, BO1, of the'Deutsche Forschungsgemeinschaft, BonnBad Godesberg, Germany

2) Enzymes:

type-I collagenase (EC 3.4.24.7), elastase (EC 3.4.21.37), gelatinase (EC 3.4.24.-)
}

phagocytosed cells and microorganisms, and for penetration of the extravascular tissue when secreted after chemotactic stimulation (1-4). Collagenase and gelatinase are released locally to degrade tissue components and thereby facilitate the migration of polymorphonuclear leukocyte to the inflammation site $(4,5)$. The proteolytic action of these enzymes is controlled by tissuedependent inhibitors of metallo-proteinases $(6,7)$. Specific inhibitors of these enzymes in plasma are $\beta$ anticollagenase $(8,9)$ and $\alpha_{2}$-macroglobulin $(10,11)$. Excessive proteolytic action, however, might damage the red blood cells and their membrane integrity (12, 13). This led us to investigate the release of polymorphonuclear leukocyte enzymes such as collagenase, gelatinase and elastase, and the secretory component, lactoferrin, in red cell concentrates over the usual storage time of 35 days. In order to evaluate the secretory capacity of these granular components, release was 
stimulated by the chemotactic peptide, $\mathrm{N}$-formyl-nleleu-phe-nle-tyr-leu, and cytochalasin B, which enhance the secretion of intracellular granula contents of the cell exterior $(5,14)$.

\section{Materials and Methods}

\section{Blood component preparation}

Ten units of fresh whole blood were used for the investigations. The blood donors met the criteria necessary for regular donation. The donation was performed between 8 and 8:30 in the morning. Blood $(500 \mathrm{ml})$ was collected into the collecting bag of dual-bag systems used for the preparation of red cell concentrates and platelet-rich plasma. The collection bag contained $70 \mathrm{ml}$ citrate-phosphate-dextrose-adenine- 1 anticoagulant solution.

After the donation and the withdrawal of the baseline samples from the bag the fresh whole blood was held at room temperature between $20^{\circ} \mathrm{C}$ and $24^{\circ} \mathrm{C}$ for one hour before starting the preparation of red cell concentrate, platelet-rich plasma and the buffy-coat. This was performed by centrifugation at $350 \mathrm{~g}$ for $15 \mathrm{~min}$ at $22^{\circ} \mathrm{C}$ without brake-supported deceleration. The platelet-rich plasma supernatant was carefully transferred into the platelet storage container of the dual-bag system. The platelet-rich plasma bags were then separated from the collection bag containing the red cell concentrate and buffy-coat, leaving the residual transfer tube at the red cell concentrate bag as long as possible for blood sample withdrawal purposes. The buffy-coat was thoroughly removed by unidirectional flow through the platelet-rich plasma transfer tube and discarded. The red cell concentrate was stored at $2-6^{\circ} \mathrm{C}$ in the refrigerator.

\section{Blood sampling}

The donor's baseline plasma leukocyte enzyme level was determined at the end of the donation, using $4 \mathrm{mI}$ EDTA-anticoagulated blood, taken for testing for infection and for the determination of the blood group.

Thereafter samples were taken at the following times from the the fresh whole blood, and from the red cell concentrate:

1. Donor, at the end of donation

2. Fresh whole blood 15 minutes after donation (room tempera- ture)

3. After preparation of red cell concentrate (day 0 ) (room temperature)

4. 1 day $(24 \mathrm{~h})$ after preparation of red cell concentrate $\left(+4{ }^{\circ} \mathrm{C}\right)$

5. 3 days after preparation of red cell concentrate

6. 6 days after preparation of red cell concentrate

7. 14 days after preparation of red cell concentrate

8. 21 days after preparation of red cell concentrate

9. 35 days after preparation of red cell concentrate

Before blood sample aliquots were removed from refrigerated red cell concentrates, the cells, which had sedimented during storage, had to be resuspended in the supernatant plasma. For this purpose, the cold red cells were gently mixed by manual shaking for no longer than one minute to avoid mechanical cell disrupture. Aliquots were then drawn into $5 \mathrm{ml}$ plastic syringes from the end of the residual platelet-rich plasma transfer tube, checking for strictly unidirectional flow to prevent microbial contamination. The first $5 \mathrm{ml}$ were discarded, and the next $5 \mathrm{ml}$ of the red cell concentrate were taken for determination of the spontaneously released leukocyte proteins. Another $3.5 \mathrm{ml}$ red cell concentrate were drawn into $1.5 \mathrm{ml}$ saline $(9 \mathrm{~g} / 1 \mathrm{NaCl})$ solution containing either leukocyte-stimulating additives or saline with no additives as a control. The leukocyte stimulators were applied directly in highly concentrated dimethylsulphoxide solutions to only the first sample from fresh whole blood, i. e. without the addition of saline to the $5 \mathrm{ml}$ content of the syringe. The contents of the syringes were immediately transferred to $5 \mathrm{ml}$-polystyrene tubes and allowed to stand at room temperature for $45 \mathrm{~min}$. The red cell concentrate tubes were again sealed under sterile conditions for further storage.

The cells were then separated from plasma or the diluted plasma by centrifugation at $3000 \mathrm{~g}$ for $15 \mathrm{~min}$ at $22^{\circ} \mathrm{C}$. The supernatants were aliquoted in $400 \mu$ portions, snap-frozen and stored at $-70^{\circ} \mathrm{C}$ until assayed (no longer than 6 months).

The red blood cell count was performed on a SYSMEX blood cell analyser. The polymorphonuclear leukocyte count was determined by manual, differential blood counts of blood smears stained by Pappenheim's stain.

\section{Stimulation of leukocyte enzyme release}

The chemoattractant hexapeptide N-formyl-nle-leu-phe-nle-tyr-leu, (Bachem, Heidelberg, Germany) and cytochalasin B were used for the stimulation of leukocytes. The final concentration of $\mathrm{N}$-formylnle-leu-phe-nle-tyr=leu was $10^{-7} \mathrm{~mol} / \mathrm{l}$, of cytochalasin B $5 \mathrm{mg} / \mathrm{l}$ (4).

Assays of leukocyte proteinases, polymorphonuclear leukocyte granula-specific lactoferrin and plasmatic enzyme inhibitors

Collagenase, gelatinase and lactoferrin in blood plasma were quantified by the sandwich-type ELISA technique (15). Elastase antigen concentration was determined by the IMAC technique using a commercially available assay (Merck, Darmstadt, Germany) $(16,17)$.

The activities of $\alpha_{1}$-proteinase inhibitor and $\alpha_{2}$-macroglobulin were determined by commercially available chromogenic substrate assays. The total protein concentrations of all samples were assayed by the biuret micro-method.

\section{Statistical data analysis}

All data obtained from samples diluted with saline solution and/or without additives were corrected for the dilution factor by comparison of the protein concentrations of the non-diluted and the salinediluted samples. Data analysis was performed with the computer software "Statgraphics" TM" (STSC Inc. and Statistical Graphics Corp., Los Angeles, USA). The results were displayed as multiple box-and-whisker plots (18). The central box covers the middle $50 \%$ of the data values of each grouping between the lower and upper quartiles, which are separated by the central lines at the medians: The "whiskers" extend to the minimum and maximum values. Unusual values occurring far away from the bulks are plotted as separate points. In these cases the whiskers extend only to those points that are within 1.5 times the interquartile range (18).

The blood cell count data are given by mean $\pm S D$, and the polymorphonuclear leukocyte secretion products by medians, if not otherwise stated.

\section{Results}

The blood donors exhibited normal blood cell counts of $4.76 \pm 0.32 \times 10^{12} / 1$ whole blood, haematocrits of 0.44 \pm 0.03 and $3.4 \pm 0.85 \times 10^{9} / 1$ polymorphonuclear leukocytes. Due to dilution with citrate-phosphate-dextrose-adenine-1 anticoagulant, the blood cell count in fresh whole blood decreased to $4.06 \pm 0.48 \times 10^{12 / 1}$, the haematocrit to $0.40 \pm 0.05$. The polymorphonuclear leukocyte count of $3.3 \pm 0.92 \times 10^{9} / 1$ was found to be 
unchanged. During the subsequent red cell concentrate preparation, the red blood cell count increased to 6.90 $\pm 52 \times 10^{12} / 1$, the haematocrit to $0.68 \pm 0.05$, while the polymorphonuclear leukocyte count of $3.3 \pm 1.2$ $\times 10^{9} / 1$ remained unchanged.

During the 35-day observation period slight haemoconcentration with increases of red blood cell count to 7.31 $\pm 0.34 \times 10^{12} / 1$ and haematocrit to $0.75 \pm 0.03$ were observed. This was presumably due to mild transpiration of water through the gas-permeable micropores of the red cell concentrate storage bag. In contrast, the polymorphonuclear leukocyte count decreased to $0.3 \pm 0.27$ $\times 10^{9} / 1$. The Pappenheim-stained blood smears of the day 35 exhibited more than $90 \%$ lymphocytes. The residual polymorphonuclear leukocytes exhibited severe alterations with degranulated cytoplasm and degraded nuclei. Additionally, granulocyte-derived cell fragments were frequently observed.

As shown in figures $1 \mathrm{a}-4 \mathrm{a}$, the plasma concentrations of the polymorphonuclear leukocyte-specific enzymes, collagenase, gelatinase and elastase, and of the polymorphonuclear leukocyte granula-specific lactoferrin during the red cell concentrate preparation procedure on day 0 remained within the reference ranges. After transfer to the refrigerator, continuous increases in the amounts of polymorphonuclear leukocyte secretory proteins were observed from the first day of storage until the end of the observation period. On the day 35 , the median con-

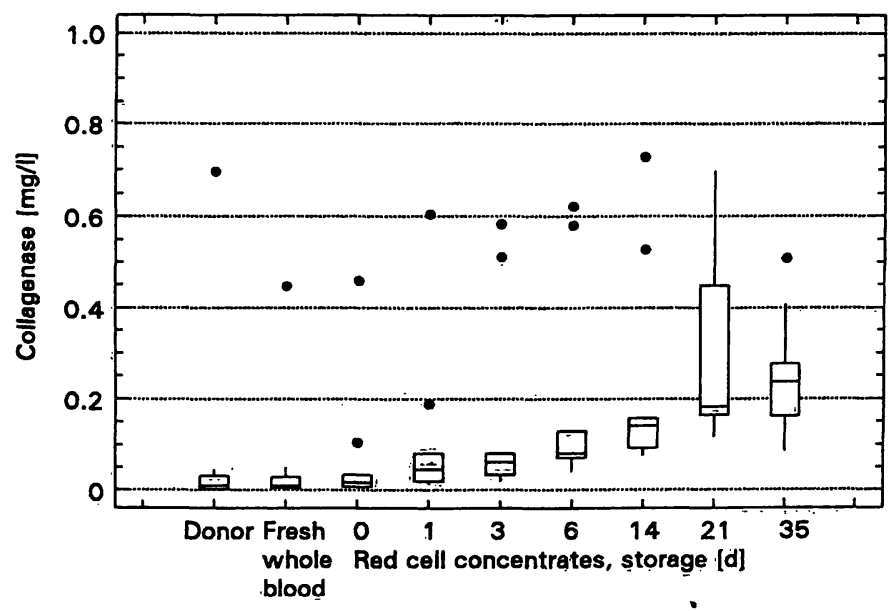

Fig. 1a Spontaneous collagenase release in red cell concentrates $(n=10)$ during 35 days storage. The samples taken on the preparation day were obtained from blood sources (donor, fresh whole blood, red cell concentrates, see below) kept at room temperature. Red cell concentrates were thereafter stored under refrigeration at $+4-6^{\circ} \mathrm{C}$ (reference range for collagenase: $0-0.05 \mathrm{mg} / \mathrm{l}$ ). The data are shown by multiple box-and-whisker plots. The boxes cover the middle $50 \%$ of each data grouping limited by the lower and upper quartiles. The central lines in the boxes reflect the medians. The "whiskers" regularly tend out to the extremes, i. e. the minimal and maximal values of each group. Unuisual values occurring far away from the bulks are plotted as separate points. In these cases the whiskers extend only to those points that are within 1.5 times the interquartile range (18).

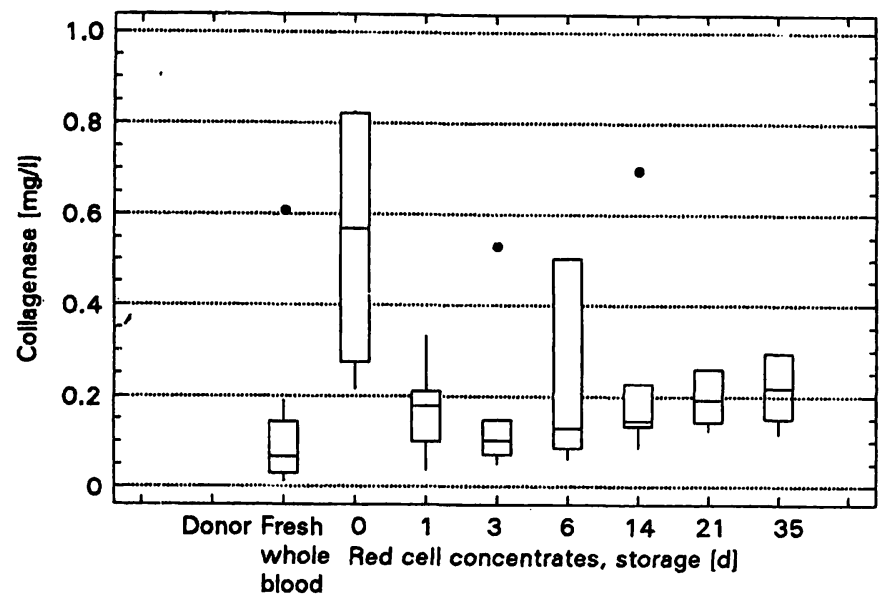

Fig. 1b Collagenase release in red cell concentrates during 35 days storage in the refrigerator under stimulation with $\mathrm{N}$-formylnle-leu-phe-nle-tyr-leu/cytochalasin B. N-formyl-nle-leu-phe-nletyr-leu was used at a final concentration of $10^{-7} \mathrm{~mol} / \mathrm{l}$, cytochalasin $B$ at $5 \mathrm{mg} / \mathrm{l}$. For further explanation see figure 1a. For testing the fresh whole blood samples the stimulators were applied as highly concentrated solutions in dimethylsulphoxide. For red cell concentrate the stimulators were diluted in $0.5 \mathrm{ml}$ saline $(9 \mathrm{~g} / \mathrm{l}$ $\mathrm{NaCl}$ ) solution per $4.5 \mathrm{ml}$ red cell concentrate. The incubation mixtures were held at room temperature for $45 \mathrm{~min}$ prior to separation of the red blood cells from plasma by centrifugation.

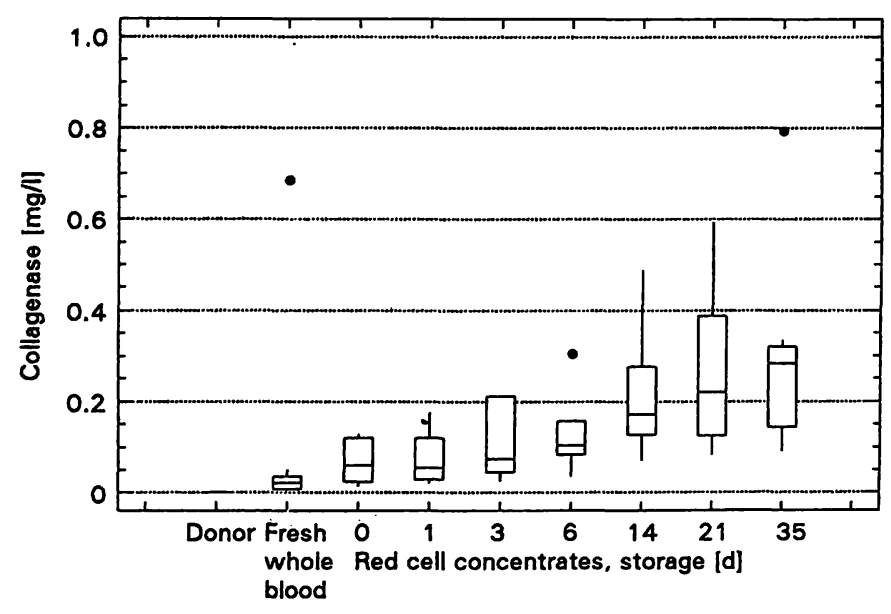

Fig. 1c Blank controls of spontaneous collagenase release in red cell concentrate during 35 days storage under refrigeration. Fresh whole blood samples were treated on the preparation day with the same dimethylsulphoxide volume applied to fresh whole blood for stimulation by $\mathrm{N}$-formyl-nle-leu-phe-nle-tyr-leu/cytochalasin B. Samples from red cell concentrate on day 0 to 35 were drawn with saline diluent. For further explanation see figures la.

centration of collagenase was approx. 20-fold, of gelatinase 6-fold, of elastase 100-fold and of lactoferrin 15fold higher than on the day of preparation.

$\mathrm{N}$-formyl-nle-leu-phe-nle-tyr-leu/cytochalasin B stimulated the release of the proteinases and lactoferrin from polymorphonuclear leukocytes in freshly donated whole blood and in red cell concentrate only up to the end of the first day of storage. As shown in figures $1 b-4 b$, the increases in the polymorphonuclear leukocyte secretory components in fresh whole blood were moderate, i. e. 


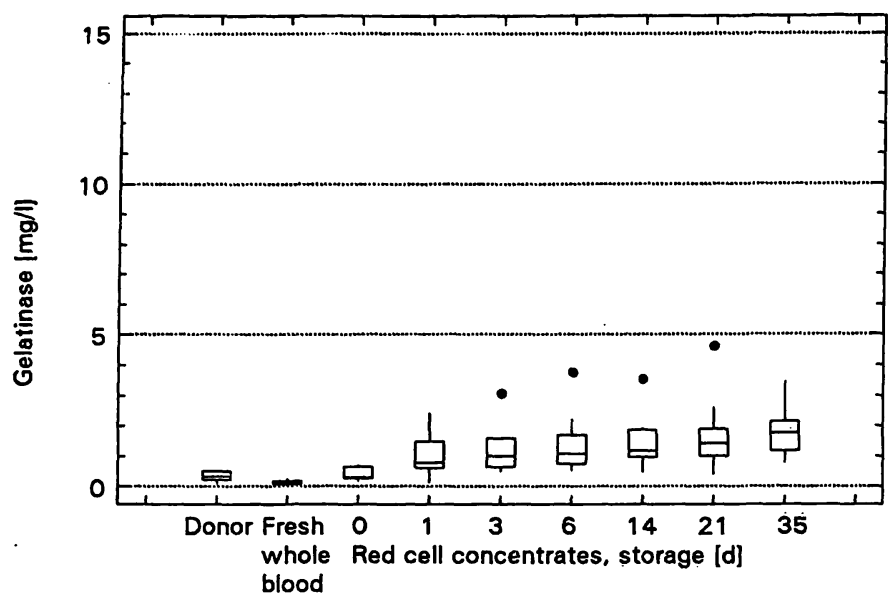

Fig. 2a Spontaneous gelatinase release in red cell concentrate during 35 days storage under refrigeration. Gelatinase reference range: $0.027-0.094 \mathrm{mg} / \mathrm{l}$. For further explanations see figure la.

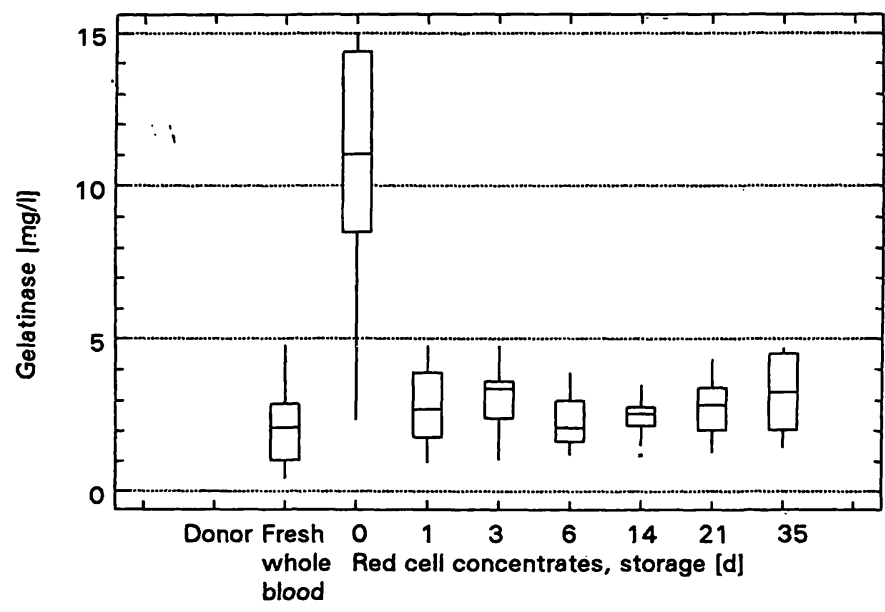

Fig. 2b Gelatinase release in red cell concentrate during 35 days storage in the refrigerator under stimulation with $\mathrm{N}$-formyl-nle-leuphe-nle-tyr-leu/cytochalasin B. For further explanations see figures $1 \mathrm{a} / \mathrm{b}$.

the median collagenase, gelatinase, elastase and lactoferrin concentrations increased 4- to 8-fold. After stimulation of freshly prepared red cell concentrates by $\mathrm{N}$-formyl-nle-leu-phe-nle-tyr-leu/cytochalasin B, the collagenase level was enhanced 50-fold, gelatinase 35-fold, elastase 70 -fold and lactoferrin 60 -fold. After overnight storage in the refrigerator the response of the polymorphonuclear leukocytes was distinctly weaker than immediately after red cell concentrate preparation; collagenase increased only 4-fold, gelatinase 3.5-fold, and elastase and lactoferrin 4- to 5-fold. On the third day of storage and thereafter, no significant effects of the stimulants were observed. The use of saline diluent to obtain higher plasma yields from the red cell concentrate led to slightly but insignificantly higher polymorphonuclear leukocyte protein secretion levels, compared with those of the undiluted and unstimulated samples. This ${ }^{\circ}$ is demonstrated by the collagenase saline blank data in figure $1 \mathrm{c}$.

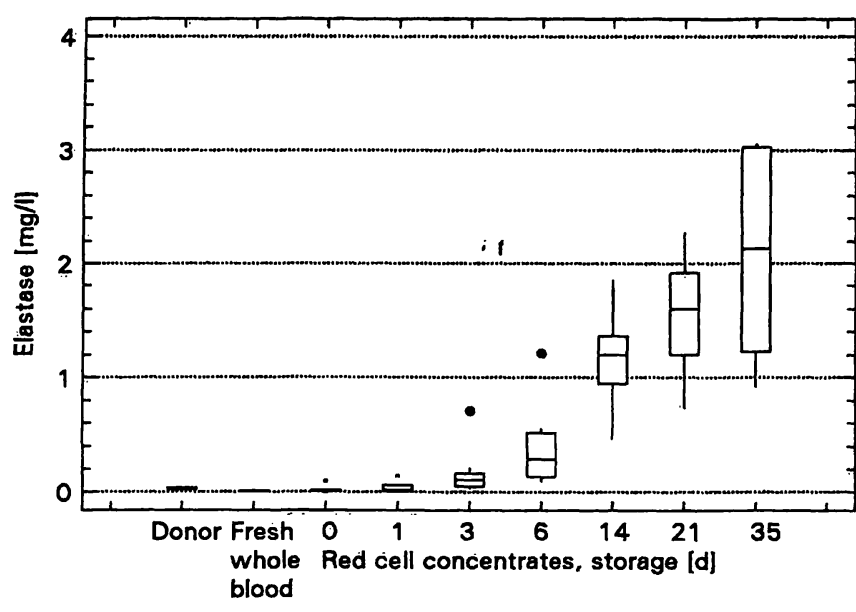

Fig. 3a Spontaneous elastase release in red cell concentrate during 35 days storage under refrigeration. Reference range for elastase: $0-0.05 \mathrm{mg} / \mathrm{l}$. For further explanations see figure la.

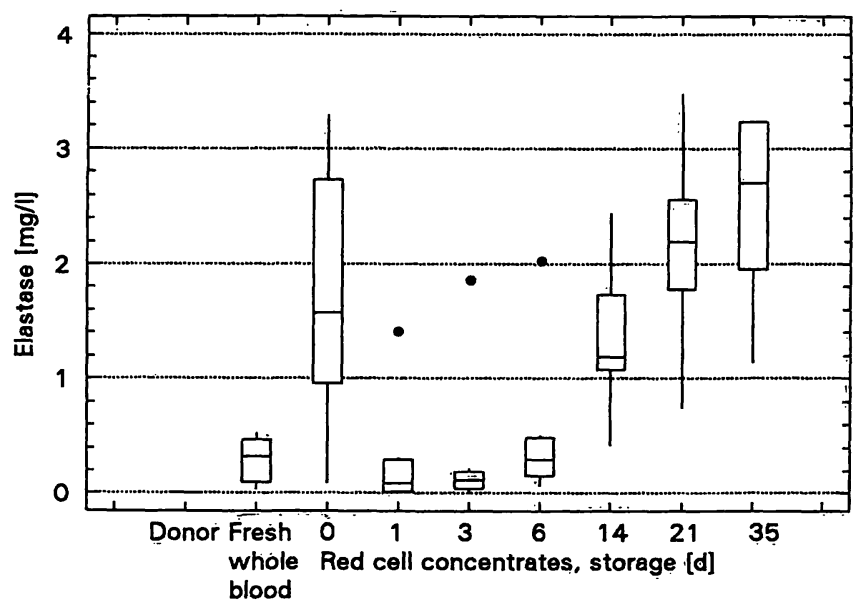

Fig. 3b Elastase release in red cell concentrate during 35 days storage in the refrigerator under stimulation with $\mathrm{N}$-formyl-nle-leuphe-nle-tyr-leu/cytochalasin B. For further explanations see figures $1 \mathrm{a} / \mathrm{b}$.

The inhibitory activities of the plasmic enzyme inhibitors, $\alpha_{1}$-proteinase inhibitor and $\alpha_{2}$-macroglobulin, decreased slightly during the observation period (figs. 5 and 6). The decrease in $\alpha_{1}$-proteinase inhibitor activity was approx. $5 \%$ over 35 days; $\alpha_{2}$-macroglobulin decreased by $20 \%$. However, these losses were found to be statistically insignificant and, particularly in the case of $\alpha_{2}$-macroglobulin, this might be due to the low number of red cell concentrates analysed.

\section{Discussion}

The red cell concentrates prepared from fresh whole blood after the removal of buffy-coat exhibited considerable leukocytic contamination. During storage the polymorphonuclear leukocyte count dropped below $10 \%$ of the initial content. The evaluated data indicate that during storage under refrigeration over 5 weeks leuko- 


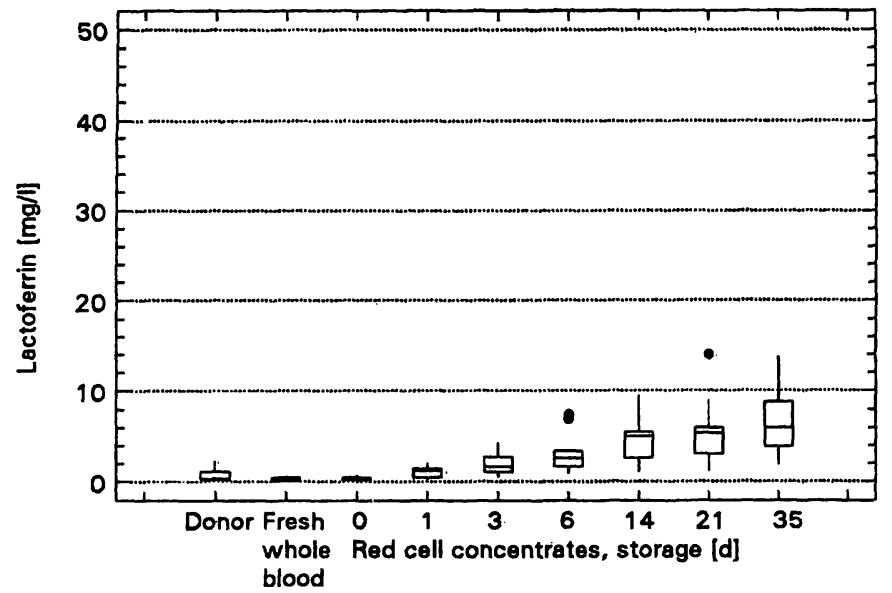

Fig. 4a Spontaneous lactoferrin release in red cell concentrate during 35 days storage under refrigeration. Reference range of lactoferrin: about $300 \mathrm{mg} / \mathrm{l}$. For further explanations see figure la.

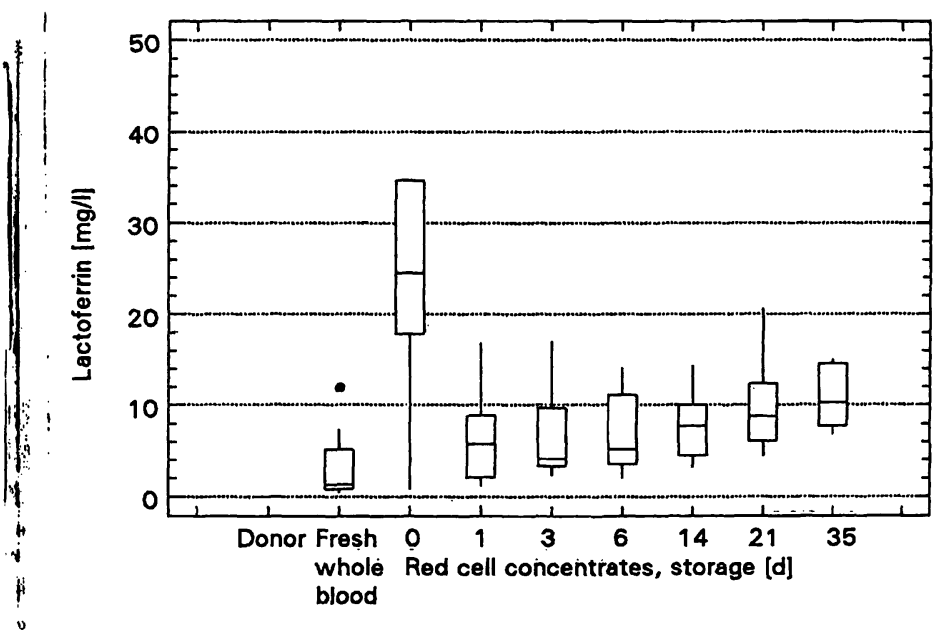

Fig. 4b Lactoferrin release in red cell concentrate during 35 days storage in the refrigerator under stimulation with $\mathrm{N}$-formyl-nle-leuphe-nle-tyr-leu/cytochalasin B. For further explanations see figure $1 \mathrm{a} / \mathrm{b}$.

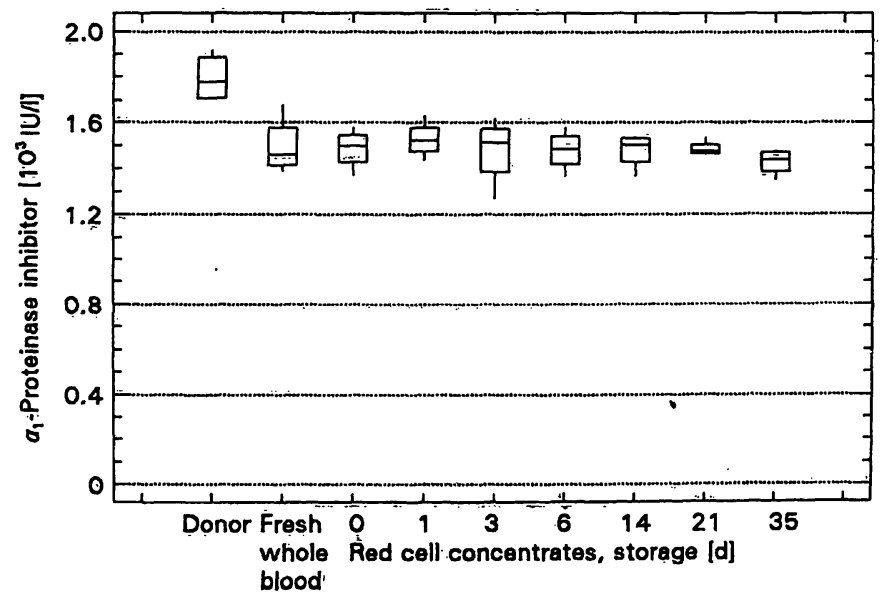

Fig. $5 \alpha_{1}$-Proteinase inhibitor in red cell concentrates during 35 days storage under refrigeration (reference range of $\alpha_{1}$-proteinase inhibitor 1.12-1.62 kIU/l). For further explanations see figure la.

cyte-specific proteinases and lactoferrin are continuously released from polymorphonuclear leukocyte, pre-

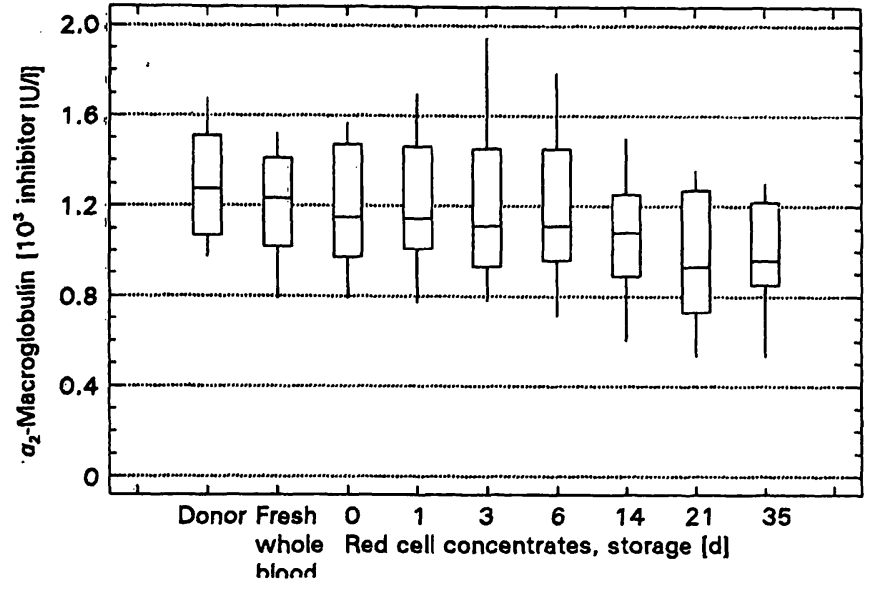

Fig. $6 \alpha_{2}$-Macroglobulin in red cell concentrates during 35 days storage under refrigeration (reference range of $\alpha_{2}$-macroglobulin $0.7-1.4 \mathrm{kIU} / \mathrm{l})$. For further explanations see figure $1 \mathrm{a}$. $\mathrm{IU}=$ Inhibitor unit

sumably due to cell death. The maximal collagenase levels spontaneously released during red cell concentrate storage were found to be only 10 to $15 \%$ of the highest spontaneously released elastase levels, both measured at the end of the observation period. Maximal unstimulated gelatinase levels were 80 to $90 \%$ of the elastase levels. Of the analysed released enzymes, elastase exhibited the highest absolute concentrations in the absence of stimulators.

Polymorphonuclear leukocytes were stimulated with $\mathrm{N}$ formyl-nle-leu-phe-nle-tyr-leu/cytochalasin B to determine the maximal amounts of proteinase which could be released from the cells and to evaluate how long the cells could respond to these'stimulators under the red cell concentrate storage conditions. The reaction of polymorphonuclear leukocytes in fresh whole blood was weaker than in red cell concentrate immediately after its preparation. This effect might be explained by a weaker response of the cells when subjected to stimulators in highly concentrated dimethylsulphoxide solution, compared with the application of stimulators prediluted in saline. It was obviously not due to rapid inhibition of the released enzymes by the larger total amount of plasma inhibitors in fresh whole blood compared with the plasma volume-reduced red cell concentrate, because the amount of lactoferrin in fresh whole blood was also considerably lower than in red cell concentrate.

In freshly prepared red cell concentrate the collagenase levels after $\mathrm{N}$-formyl-nle-leu-phe-nle-tyr-leu/cytochala$\sin B$ treatment were 3-fold higher than the maximal collagenase levels after 35 days of storage. Similar observations were made for gelatinase. However, the highest enzyme concentrations released under stimulated conditions were evaluated for gelatinase, and not for elastase. Gelatinase release was about 6 times greater than 
the $\mathrm{N}$-formyl-nle-leu-phe-nle-tyr-leu/cytochalasin B-induced elastase release, and 4 times greater than the maximal elastase release after 35 days storage. In contrast, the maximal amount of elastase released by $\mathrm{N}$ formyl-nle-leu-phe-nle-tyr-leu/cytochalasin B was $60 \%$ of that secreted during the 35 days of storage.

The results confirm that collagenase and gelatinase are more easily released by $\mathrm{N}$-formyl-nle-leu-phe-nle-tyrleu/cytochalasin B than is elastase. Similar observations have been reported by Schettler et al. (4). The intracellular gelatinase storage pool seemed to be greater than the elastase pool, but during the entire storage period of red cell concentrate, the relative release or detectable plasma amount of collagenase and gelatinase was found to be smaller than that of elastase. This discrepancy might be due either to higher stability of the intracellular collagenase and gelatinase storage granules compared with elastase after cell death, or to intracellular inactivation of the enzymes during storage, e. g. by intracellular oxidases, or to rapid inactivation of these enzymes by plasma or cellular inhibitors.

The weak stimulatory effects of $\mathrm{N}$-formyl-nle-leu-phenle-tyr-leu/cytochalasin B on the polymorphonuclear leukocytes after storage of the red cell concentrate for 1 day under refrigeration, indicates that the cells had lost nearly all of their secretory ability, due either to loss of mitochondrial ATP generation under refrigeration, or to cell death. The $\alpha_{1}$-proteinase inhibitor activity levels in red cell concentrate were not significantly changed during the storage period and remained sufficiently high to inhibit the released elastase. However, the slight decrease in $\alpha_{1}$-proteinase inhibitor activity during 35 days might be due not only to neutralization of elastase and other proteinases or to oxidative inactivation by polymorphonuclear leukocyte oxidoreductases such as myeloperoxidase or polymorphonuclear leukocyte-derived reactive oxidants $(19,22)$, but also to proteolytic degradation by polymorphonuclear leukocyte col- lagenase (23). In contrast, the $\alpha_{2}$-macroglobulin activity decreased more significantly, perhaps as a result of inhibition by released polymorphonuclear leukocyte enzmyes, such as collagenase, gelatinase, elastase, cathepsin $G$ and others $(11,24)$. In addition, the oxidative inactivation of $\alpha_{2}$-macroglobulin by polymorphonuclear leukocyte-derived reactive oxidants mentioned above might also have reduced the $\alpha_{2}$-macroglobulin levels $(19,20)$.

The proteinases in the red cell concentrate might have deleterious biological effects such as degradation of plasma proteins and presumably also of erythrocyte surface membrane proteins. The proteolytically degraded plasma proteins are probably of minor importance, because the small plasma volume after transfusion is rapidly diluted in the recipient's plasma. A proteolytic alteration of red blood cell membranes, however, might diminish the stability and the survival time of the transfused red blood cells. Deleterious effects of enzymes on red blood cell membranes with negative consequences for the red blood cells has been observed by other authors $(12,13)$. When a large number of transfusions is performed this might overstress the clearance functions of the monocyte macrophage elimination system of the patient. Specifically, the enzymes inducing connective tissue breakdown, i. e. collagenase, gelatinase and elastase, might be capable of aggravating the effects of capillary damage as induced by pathomechanisms such as shock and sepsis, or as a complication of massive blood transfusions (24). Therefore, the depletion of red cell concentrate of polymorphonuclear leukocytes might improve the storage quality and the biocompatibility of the blood preparations.

\section{Acknowledgement}

The authors are gratefully indebted to Mrs. H. Hoffmann and Mrs $G$. Witzel for excellent technical assistence. In addition they wish to thank Mrs. G. Delany for linguistic advice.

\section{References}

1. Bretz, U. \& Baggiolini, M. (1974) Biochemical and morphological characterization of azurophil and specific granules of human neutrophilic polymorphonuclear leucocytes. J. Cell Biol. 63, 251-269.

2. Spitznagel, J. K., Dalldorf, F. G., Leffel, M. S., Folds, J. D. Welsh, I. R. T., Cooney, M. H. \& Martin. L. E. (1974) Character of azurophil and specific granules purified from human polymorphonuclear leukoytes. Lab. Invest. 30 774-785.

3. Dewald, B., Bretz, U. \& Baggiolini, M. (1992) Release of gelatinase from a novel secretory compartment of human neutrophils. J. Clin. Invest. 84, 518-525.

4. Schettler, A., Thorn, H., Jockusch, B. M. \& Tschesche, H (1991) Release of proteinases from stimulated polymorphonuclear leukocytes. Evidence for subclasses of the main granule types and their association with cytoskeletal components. Eur. J. Biochem. 197, 197-202.

5. Bakowski, B. \& Tschesche, H. (1992) Migration of polymorphonuclear leukocytes throụgh human amnion membrane - A scanning electron microscopic study. Biol. Chem. HoppeSeyler 373, 529-546.

6. De Clerck, Y. A., Yean, T.-D., Lu, H. S., Ting, J. \& Langley, K E. (1991) Inhibition of autoproteolytic activation of interstitial procollagenase by recombinant metalloproteinase inhibitor M1/TIMP-2. J. Biol. Chem. 266, 3893-3899.

7. Howard, E. W., Bullen, E. C. \& Banda, M. J. (1991) Preferential inhibition of 71 - and $92 \mathrm{kDa}$ gelatinases by tissue inhibitor of metalloproteinases-2. J. Biol. Chem. 266, 13070-13075.

8. Wooley, D. E., Akroyd, C., Evanson, J. M., Soames, J. V. \& Davies, R. M. (1978) Characterisation and serum inhibition of neutral collagenase from cultured dog gingival tissue. Biochim. Biophys. Acta 522, 205-217. 
9. Wooley, D. E., Roberts, D. R. \& Evanson, J. M. (1976) Small molecular weight $\beta 1$ serum protein which specifically inhibits human collagenase. Nature (Lond.) 261, 325-327.

10. Eisen, A. Z., Bauer, E. A. \& Jeffrey, J. J. (1971) Human skin collagenase. The role of serum alpha-globulins in the control of activity in vivo and in vitro. Proc. Natl. Acad. Sci. USA 68, 248-251.

11. Sottrup-Jensen, L. \& Birkedal-Hansen, H. (1989) Human fibroblast collagenase $\alpha_{2}$-macroglobulin interactions. Localization of cleavage sites in the bait regions of five mammalian $\alpha_{2}$-macroglobulins. J. Biol. Chem. 264, 393-401.

12. Arend, P. \& Malchow, H. (1974) Antigenic alteration of red cell surfaces exposed to enzymatic actions of autologous polymorphonuclear leukocytes. Vox Sang. 26, 344-360.

13. Högman, C. F., Hedlund, K., Akerblom, O. \& Venge, P. (1978) Red cell preservation in protein poor media. I. Leukocyte enzymes as a cause of hemolysis. Transfusion 18, 233-244.

14. Sklar, L. A. (1986) Ligand-receptor dynamics and signal amplification in the neutrophil. Adv. Immunol. 39, 95-143.

15. Bergmann, U., Michaelis, J., Oberhoff, R., Knäuper, V., Beckmann, R. \& Tschesche, H. (1989) Enzyme linked immunosorbent assays (ELISA) for the quantitative determination of human leukocyte collagenase and gelatinase. J. Clin. Chem. Clin. Biochem. 27, 351-359.

16. Dreher, M., Gunzer, G., Helger, R. \& Lang, H. (1989) An automated homogeneous enzyme immunoassay for human PMN elastase. In: "2 ${ }^{\text {nd }}$ Vienna Shock Forum" (Schlag, G. \& Redl, H., eds.) Alan R. Liss Inc., New York, pp. 707-710.

17. Neumann, S., Gunzer, G., Hennrich, N. \& Lang, H. (1984) "PMN elastase assay": Enzyme immunoassay for human polymorphonuclear elastase complexed with $\alpha_{1}$-proteinase inhibitor. J. Clin. Chem. Clin. Biochem. 22, 693-697.
18. McGill, R., Turkey, J. W. \& Larsen, W. A. (1978) Variations of box plots. Amer. Statistician 32, 12-16.

19. Weiss, S., Lampert, M. B. \& Test, S. T. (1983) Long-lived oxidants generated by human neutrophils: Characterization and bioactivity. Science 222, 625-628.

20. Stief, T. W., Martin, E., Digon, J., Vinuesa, M. \& Rodriguez, J. $M$. (1990) Inactivation of human $\alpha_{2}$-macroglobulin by reactive oxidants. Blut 60,148 , Abstr. no. 172.

21. Beatty, K., Bieth, J. \& Travis, J. (1980) Kinetics of association of serine proteinases with native and oxidated $\alpha_{1}$-proteinase inhibitor and $\alpha_{1}$-antichymotrypsin. J. Biol. Chem. 255, 3931-3934.

22. Beckmann, J., Mehlich, A., Feldmann, A., Wenzel, H. R. \& Tschesche, H. (1989) Semisynthetic met 15-aprotinin: Redox reactions and their influence on inhibitor activity. In: IntracelLular Proteolysis - Mechanisms of Regulations (Katunuma, N. \& Kominami, E., eds.) Proceedings of the 7th ICOP Meeting, Shimoda, Japan, Japan Scientific Societies Press, Tokyo, pp. $361-368$.

23. Knäuper, V., Reinke, H. \& Tschesche, H. (1990) Inactivation of $\alpha_{1}$-proteinase inhibitor by human PMN leukocyte collagenase. FEBS Lett. 263, 355-357.

24. Jochum, M., Mempel, W. \& Fritz, H. (1984) Release of granulocytic lysosomal enzymes and concentrations of plasma factors in stored blood. International Society of Blood Transfusion Meeting, Munich, Germany, No. P9-02, p. 169 (abstr.)

Dr. med. Dr. rer. nat. Hans-Jörg Hertfelder Institut für Experimentelle Hämatologie und Transfusionsmedizin der Universität Bonn Sigmund-Freud-Straße 25

D-53105 Bonn

Germany 
